Aim of this study was to examine the effects of aromatase inhibitors (Als), which are used in every phase of breast cancer treatment, on the bone mineral density (BMD) of patients with early-stage breast cancer.

Material and methods: Menopausal female patients who were diagnosed with stages 1-3 breast cancer and who were planned for anastrazole or letrozole as adjuvant therapy were examined. After the patients' BMD was measured, 45 patients without osteoporosis were included in the study. Six months after Al therapy started, the patients' BMD was measured again. Results: In this study, we tried to show that there was a statistical difference in the BMD of 45 patients before and 6 months after treatment. Among all measurements (femur and lumbar $T$-scores), the femur Z-score $(p=0.52)$ was the only score that was not statistically significant. Statistical significance $(p<0.01)$ was detected in comparative analysis of the other measurements. According to this analysis, a significant loss of BMD was seen even in the first six months after Al treatment was introduced.

Conclusions: Female patients with breast cancer are at higher risk for bone loss and fractures than healthy women. In this study, we showed the negative effects on BMD of aromatase inhibitor therapy, one of the main contributions to osteoporosis in women with breast cancer. This study is the first to quantify the short-term effect of $\mathrm{Al}$ treatment on BMD in postmenopausal women with breast cancer.

Key words: aromatase inhibitor breast cancer, bone mineral density, osteoporosis.

Contemp Oncol (Pozn) 2015; 19 (5): 374-377 DOI: $10.5114 /$ wo.2014.45305

\section{Aromatase inhibitor treatment for breast cancer: short-term effect on bone health}

\author{
Gökhan Erbağ ${ }^{1}$, Kazım Uygun ${ }^{2}$, Emine Binnetoğlu ${ }^{1}$, Ayşe Nurdan Korkmaz ${ }^{3}$, \\ Mehmet Aşık ${ }^{4}$, Hacer Şen ${ }^{4}$, Fahri Güneş ${ }^{4}$, Mustafa Eroğlư ${ }^{4}$, Ferhat Gökmen ${ }^{5}$, \\ Süleyman Temiz ${ }^{2}$
}

\author{
'Department of Internal Medicine, Faculty Of Medicine, Kocaeli University, \\ Kocaeli, Turkey \\ 2Department of Oncology, Faculty Of Medicine, Kocaeli University, Kocaeli, Turkey \\ ${ }^{3}$ Department of Nuclear Medicine, Kocaeli State Hospital, Kocaeli, Turkey \\ ${ }^{4}$ Department of Internal Medicine, Faculty Of Medicine, Çanakkale Onsekiz Mart \\ University, Çanakkale, Turkey \\ 5Department of Physical Therapy and Rehabilitation, Faculty of Medicine, Çanakkale \\ Onsekiz Mart University, Çanakkale, Turkey
}

\section{Introduction}

Breast cancer (BC) is the most common type of cancer in women [1]. The life expectancy of patients with BC has increased in the last 10 years, linked to advances in imaging, diagnosis, and treatment. One of the most important reasons for the increase in life expectancy is the introduction of aromatase inhibitor (Al) use in treatment [2].

In menopausal women, circulating oestrogen is formed by the aromatisation of androgens to oestrogen in adipose, liver, and muscle tissue. The aromatase enzyme found in these tissues, a cytochrome p450 enzyme, catalyses the last stage of oestrogen synthesis. In addition, many breast tumour tissues have shown the presence of aromatase enzyme activity forming local oestrogen sources [3]. Aromatase inhibitor lowers oestrogen levels by blocking the cytochrome p450 enzyme. However, because Als effectively deplete residual oestrogen levels, they are associated with accelerated bone loss and increased risk of fracture [4]. Although the type and duration of use are not clearly defined, Als are recommended by standard treatment guidelines in one stage of adjuvant treatment of postmenopausal patients with breast cancer with positive hormone receptor (HR) [5].

Seventy-five per cent of the total bone density loss over a woman's lifetime occurs during the postmenopausal period. In the first 15-20 years of this period, $30 \%$ of the total bone density loss occurs [6]. Although $52 \%$ to $66 \%$ of this loss occurs due to oestrogen deficiency, the rest stems from aging [7]. An explicit decrease in bone mineral density (BMD) is observed along with a decrease in circulating oestrogen levels during the postmenopausal period due to the increased use of Al.

Intergroup exemestane studies (IES) [8] indicate that bone loss is relatively predictable, so the risk of developing osteoporosis while a patient is taking an aromatase inhibitor, before starting endocrine therapy, occurs after three years for women with normal BMD. In this study, in contrast to previous studies, we aim to show that the decrease in $B M D$ related to $A l$ treatment occurs even in the early stage of treatment.

\section{Material and methods}

The study population was selected from patients undergoing follow-up at the oncology department outpatient clinic of Kocaeli University Medical Faculty Hospital. The project was approved by the Kocaeli University Medical 
Faculty Ethics Committee. Patients were informed about the tests, and written consent was obtained. In premenopausal women with breast cancer we prefer to use tamoxifen to protect the endometrium, but in postmenopausal women with breast cancer we use aromatase inhibitors. Postmenopausal patients with positive diagnosis of stage 1-3 breast cancer HR and planned Al (anastrazole, letrozole) adjuvant treatment were included in the study. Use of medications such as Coumadin, heparin, and steroids, metastasis found on second measurements, known rheumatic diseases, hyperthyroidism, severe chronic diseases or malabsorption, and bisphosphonate and calcium use for osteoporosis diagnosis were exclusion criteria. Patients' BMD was measured before Al treatment. Patients without known osteoporosis were included in the study, and Al treatment began. Fifty patients were included in the study. During this period, no patient was given calcium or vitamin D for any reason. During follow-up, some patients were excluded from the study: four patients developed metastases; one patient developed arthralgia linked to medication, and Al treatment was discontinued. The BMD of the 45 patients remaining in the study at the end of the 6-month treatment was measured to determine the shortterm effects of the treatment on BMD.

\section{Bone mineral density measurements}

In this study, a DEXA device, Hologic Discovery A(S/N 81053) QDR 4500 series, was used. The working principle of the device is as follows: Radiation first passes through a calibration disk containing the absorption material, and then the patient. Then values from the patient are rated according to the values from the absorption material. Problems due to variations in the energy spectrum are resolved by the internal automatic reference system. Bone mineral density was measured with the patient supine, as recommended by the manufacturer. The BMD measurement results were presented as the BMD, T-score, and $Z$-score using statistical concepts. The Z-score is defined as the standard deviation between the patient's bone mass compared with normal reference values for her gender and age. The T-score is defined as the standard deviation between the patient's bone mass and that of a young

Table 1. Demographic characteristics of patients

\begin{tabular}{|l|l|}
\hline Age (year) & $58.1 \pm 8.8$ \\
\hline BMI $\left(\mathrm{kg} / \mathrm{m}^{2}\right)$ & $31.3 \pm 4.0$ \\
\hline Age of menarche (years) & $13.2 \pm 1.1$ \\
\hline Duration of menopause (years) & $9.5 \pm 7.5$ \\
\hline Number of births & $2.6 \pm 1.2$ \\
\hline BMI - body mass index & \\
\hline
\end{tabular}

Table 2. Bone mineral density values before and after treatment

\begin{tabular}{|c|c|c|c|c|c|c|}
\hline & $\begin{array}{l}\text { Lumbar } \\
T \text {-score }\end{array}$ & $\begin{array}{l}\text { Lumbar } \\
\text { Z-score }\end{array}$ & $\begin{array}{l}\text { Lumbar BMD } \\
\qquad\left(\mathrm{g} / \mathrm{m}^{2}\right)\end{array}$ & $\begin{array}{l}\text { Femur } \\
T \text {-score }\end{array}$ & $\begin{array}{l}\text { Femur } \\
\text { Z-score }\end{array}$ & $\begin{array}{c}\text { Femur BMD } \\
\left(\mathrm{g} / \mathrm{cm}^{2}\right)\end{array}$ \\
\hline Before treatment & $-0.71 \pm 0.95$ & $-0.01 \pm 1.02$ & $1.011 \pm 0.161$ & $-0.79 \pm 0.96$ & $0.26 \pm 0.98$ & $0.880 \pm 0.071$ \\
\hline After treatment & $-1.06 \pm 1.06$ & $-0.30 \pm 0.15$ & $0.947 \pm 0.023$ & $-1.30 \pm 0.14$ & $0.04 \pm 0.11$ & $0.820 \pm 0.155$ \\
\hline$P$ value & $<0.01$ & $<0.01$ & $<0.01$ & $<0.01$ & 0.052 & $<0.01$ \\
\hline
\end{tabular}

adult with peak bone mass. Bone mineral density is given as BMD $\mathrm{g} / \mathrm{cm}^{2}$. According to World Health Organization guidelines, a T-score between -1.0 and -2.5 standard deviation (SD) compared to young adults is accepted as osteopaenia while a $T$-score value of -2.5 SD or lower compared to young adults is accepted as osteoporosis.

\section{Statistical analysis}

Results were evaluated using the program Statistical Package for Social Sciences (SPSS) 16.0. To compare the patients' initial readings with those at the end of the 6-month treatment, the paired sample t-test was used. To evaluate the patients' prognosis and BMD loss, the chisquared test was used. A $p<0.05$ value was accepted as statistically significant.

\section{Results}

The demographic characteristics of the 45 women with $B C$ included in the BMD study are given in Table 1. Although the initial BMD readings, $T$-scores, and Z-scores of 19 patients were within normal intervals (42.4\%), 26 patients had values compatible with osteopaenia (57.8\%). The patients were followed up during Al treatment. The second DEXA readings were taken six months after the Al treatment started. The femur and lumbar T-scores, $Z$-scores, and BMD readings after the six-month treatment were compared with the first readings. When the results were compared, the patients' lumbar BMD, T-score, and $Z$-score differed significantly $(p<0.01)$. In addition, the femur BMD and $T$-score differed significantly $(p<0.01)$. Of the readings, only the femur $Z$-score was not statistically significant, but it had decreased ( $p=0.052)$ (Table 2). The Al treatment are shown in Fig. 1.

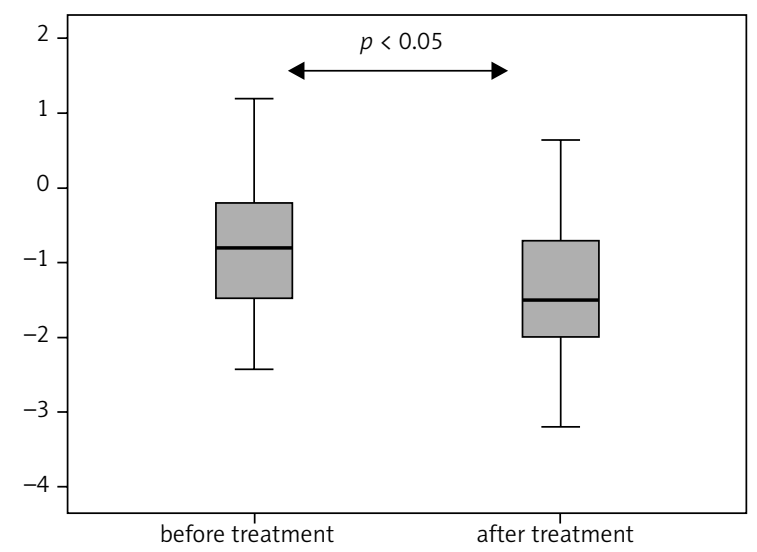

Fig. 1. The decreases in the patients' femur and lumbar $T$-scores after Al treatment decreases in the patients' femur and lumbar $T$-scores after 
Table 3. Relationship between reduction in femur and lumbar BMD and prognostic factors

\begin{tabular}{lcccccc} 
& Stage 1 & Stage 2 & P value & Grade 1 & Grade 2-3 & $\boldsymbol{P}$ value \\
\hline Femur BMD & $0.0622 \pm 0.070$ & $0.0633 \pm 0.043$ & NS & $0.0781 \pm 0.055$ & $0.0530 \pm 0.067$ \\
Lomber BMD & $0.0684 \pm 0.073$ & $0.0550 \pm 0.057$ & NS & $0.0423 \pm 0.059$ & NS \\
\hline
\end{tabular}

NS - not significant

Taking account of the patients' initial situation (normal, osteopaenia, osteoporosis), a McNemar analysis was conducted. According to the 6-month measurements for the 19 patients who had normal femur and lumbar $T$ - and $Z$-scores on the initial measurements, 9 had developed osteopaenia and osteoporosis $(p<0.05)$. Of the patients with osteopaenia identified by the initial readings, seven had developed osteoporosis after six months of Al treatment $(p<0.05)$.

The relationship between the decrease in the patients' femur and lumbar BMD readings and prognostic factors is shown in Table 3. The increase in the patients' tumour stages and grades did not cause the decrease in the BMD measurements.

\section{Discussion}

The aim of this study was to show that osteoporosis develops in patients undergoing Al treatment for BC. This study showed that the patients' lumbar BMD, T-scores, and Z-scores decreased significantly. In addition, the patients' femur BMD and T-scores decreased significantly. In addition to showing the effect of Al treatment on the development of osteoporosis, as in previous studies, we demonstrated that even in the first six months of treatment there is a definite negative effect on bone health.

In recent years, many studies on the effects of $B C$ on bones have been conducted. These studies have shown that $\mathrm{BC}$ has important effects on bone health. Many of the effects are due to chemotherapy (CT) and early induction of menopause due to ovarian ablation together with, in later periods, the start of Al treatment for HR-positive postmenopausal patients causing suppression of oestrogen after menopause. Bączyk et al. demonstrated that serum oestrogen levels have a protective effect on the BMD of postmenopausal women [9]. The imbalance between osteoclasts and osteoblasts leads to osteopaenia and, subsequently, osteoporosis. Oestrogen affects two receptors (ER $\alpha$ and $E R \beta$ ) in osteoblasts, osteoclasts, and stromal cells of the bone marrow. In particular, oestrogen regulates osteoclasts [10] and inhibits the cytokines that activate bone resorption in osteoblasts and stromal cells in bone narrow [11]. We believe that aromatase inhibitors prevent the formation of oestrogen and lead to osteoporosis in this way.

Previous studies have shown that $A l$ reduces BMD in postmenopausal women, but tamoxifen (TMX) had the opposite effect $[12,13]$. Eastell et al., in a study of patients with breast cancer after menopause, found that after two years of anastrazole and letrozole treatment hip and lumbar vertebra bone mineral density had decreased: the risk of hip fracture for women using anastrazole was $7 \%$, and for women using letrozole $3.7 \%$. The researchers concluded these results were linked to aromatase inhibition of residual circulating oestrogen in women after menopause and the removal of the antiresorptive effect of oestrogen on bone [14]. The Anastrazole, Tamoxifen, Alone or in Combination (ATAC) study showed the long-term effects (five years) of Al in women with breast cancer. That study compared anastrazole and tamoxifen [15]. In our study, we aimed to illustrate the negative effects of Al use on BMD in the light of previous studies. The measurements showed that the lumbar and femur BMD decreased, even within the first 6 months. When the BMD loss is evaluated with the patients' tumour stage and grade, we showed the decrease in the lumbar and femur $T$ - and $Z$-score readings was independent of tumour stage and grade. These results support the view that the patients' bone loss was primarily due to Al treatment.

In this study, we observed that seven patients who had osteopaenia before Al treatment developed osteoporosis within six months. Based on these data, short-term Al treatment, especially in patients with osteopaenia, may cause osteoporosis. We also believe there is a definite increase in the incidence of fracture. Bajetta et al., in a study of women with $\mathrm{BC}$ after menopause during three months of aromatase inhibitor treatment, found an increase in formation markers and resorption markers and showed that bone remodelling increased. This study supports the concern that letrozole, anastrazole, and exemestane use increases bone turnover markers and reduces BMD, increasing the risk of fracture [16]. Considering these data, especially for patients with osteopaenia, adding bisphosphonate to Al treatment is advantageous. The Austrian Breast and Colorectal Cancer Study Group (ABCSG) [17] and the Effect of monthly oral ibandronate on anastrozole-induced bone loss during adjuvant treatment for breast cancer (ARIBON) studies [18] on patients before menopause found that adding intravenous zoledronic acid [19], ibandronic acid, or risedronate [20] to anastrazole treatment preserved BMD and prevented bone loss. The most recent studies observed that even two years after ceasing bisphosphonate treatment, BMD was preserved in patients with BC [18]. Although similar studies state that bisphosphonate therapy is helpful for this patient group, another view for managing patients undergoing Al treatment has been proposed. Adequate intake of calcium and vitamin D, a healthy lifestyle, and regular (12-24 month) follow-up dual energy X-ray absorptiometry scanning should be routine. However, the role of prophylactic bisphosphonates is uncertain. The significance of the decrease in BMD due to Al treatment within the short period of our study (6 months) supports the proposal of applying bisphosphonate therapy to patients undergoing Al treatment.

In conclusion, this study is the first to quantify the short-term effect of Al treatment on BMD in postmeno- 
pausal women with breast cancer. The most important point emphasised by this study is that the negative effect of treatment on bone health was definitively observed within the first six months. The severity of bone loss within this short period shows that more care must be taken in Al treatment of patients, especially regarding osteoporosis. For patients with osteopaenia, although adding bisphosphonate treatment from the beginning of treatment is known to reduce the risk of bone fractures, the topic is still controversial. All patients with BC should be carefully evaluated for osteoporosis. In particular, when Al treatment is to be started, patients' bone health should be more carefully examined. Patients with osteopaenia and osteoporosis should be closely monitored, and necessary treatment should be started as soon as possible to prevent the development of fracture risk in this patient group.

The authors declare no conflict of interest.

\section{References}

1. Jemal A, Siegel R, Ward E, Murray T, Xu J, Smigal C, Thun MJ. Cancer statics. CA Cancer J Clin 2006; 56: 106-30.

2. American Cancer Society. Breast cancer facts \& figures 2005 2006. Atlanta (GA): American Cancer Society Inc; 2005.

3. Chen S, Ye J, Kijima I, Kinoshita Y, Zhou D. Positive and negative transcriptional regulation of aromatase expression in human breast cancer tissue. J Steroid Biochem Mol Biol 2005; 95: 17-23.

4. Coombes RC, Kilburn LS, Snowdon CF, et al. Survival and safety of exemestane versus tamoxifen after 2-3 years tamoxifen treatment (Intergroup Exemestane study): a randomised controlled trial. Lancet 2007; 369: 559-70.

5. Winer EP, Hudis C, Burstein HJ, et al. American Society of Clinical Oncology technology assessment on the use of aromatase inhibitors as adjuvant therapy for postmenopausal women with hormone receptor-positive breast cancer: status report 2004. J Clin Oncol 2005; 23: 619-29.

6. Yıldırım A. Menopozda oluşan fizyolojik değişiklikler (Physiological changes that occur in menopause). Klinik Menopoz Değerlendirme ve Yönetim. 1. Baskı, Eskişehir: Gestet basımevi, 1996; 1-13.

7. Madazlı R, Ocak V. Diabet hastalığı olan kadınlarda hormon replasman tedavisi (Hormone replacement therapy in women with diabetes disease). Menopoz Tedavisi ve Kanser. İstanbul: Nobel Tip Kitabevleri, 2001; 807-14.

8. Coleman RE, Banks LM, Girgis SI, et al. Skletal effects of exemestane on bone mineral density, bone biomarkers and fracture incidence in postmenopausal women with early breast cancer participating in the intergroup exemestane study (IES): a randomised controlled study. Lancet Oncol 2007; 8: 119-27.

9. Bączyk G, Opala T, Kleka P, Chuchracki M. Multifactorial analysis of risk factors for reduced bone mineral density among postmenopausal women. Arch Med Sci 2012; 8: 332-41.

10. Pacifici R. Cytokines, estrogen and postmenopausal osteoporosis: the second decade. Endocrinology 1998; 139: 2659-61.

11. Rogers A, Eastell R. Circulating osteoprotegerin and receptor activator for nuclear for NF kappa B ligand (RANKL): clinical utility in metabolic bone disease. J Clin Edocrinol Metab 2005; 90: 151-4.

12. Coleman RE. Effect of anastrozole on bone mineral densityand bone fractures: results from the 'arimidex' (anastrozole), Tamoxifen, Alone or in Combination (ATAC) trial. Eur J Cancer 2004; 2: 140

13. Goss PE, Ingle JN, Pater JL, et al. Late extended adjuvant treatment with letrozole improves outcome in women with early-stage breast cancer who complete 5 years of tamoxifen. J Clin Oncol 2008; 26: 1948-55.
14. Eastell R, Hannon R. Long-term of aromatase inhibitors on bone. J Steroid Biochem Mol Biol 2005; 95: 151-4.

15. Eastell R, Adams J, Clack G, Howell A, Cuzick J, Mackey J, Beckmann MW, Coleman RE. Long-term effects of anastrozole on bone mineral density: 7-year results from the ATAC trial. Ann Oncol 2011; 22: 857-62. doi: 10.1093/annonc/mdq541.

16. Bajetta E, Zilembo N, Bichisao E. Endocrine effects of nonsteroidal aromatase inhibitors and their clincal impact. I Clin Oncol 2002; 20: 3039-40.

17. Gnant MF, Mlineritsch B, Luschin-Ebengreuth G, et al. Zoledronic acid prevents cancer treatment-induced bone loss in premenopausal women receiving adjuvant endocrine therapy for hormone-responsive breast cancer: a report from the Austrian Breast and Colorectal Cancer Study Group. J Clin Oncol 2007; 25: 820-8.

18. Lester JE, Gutcher SA, Ellis SP, et al. Effect of monthly oral ibandronate on anastrozole induced bone loss during adjuvant treatment for breast cancer: one-year results from the ARIBON study. I Clin Oncol 2007; 25: 16.

19. Brufsky A, Harker WG, Beck JT, et al. Zoledronic acid inhibits adjuvant letrozole-induced bone loss in postmenopausal women with early breast cancer. J Clin Oncol 2007; 25: 829-36.

20. Delmas PD, Balena R, Confravreux E, Hardouin C, Hardy P, Bremond A. Bisphosphonate risedronate prevents bone loss in women with artificial menopause due to chemotherapy of breast cancer: A double-blind, placebocontrolled study. J Clin Oncol 1997; 15: 955-62.

\section{Address for correspondence}

Gökhan Erbağ, MD

Department of Internal Medicine

Faculty of Medicine, Kocaeli University

Kocaeli, Turkey

fax +902623037575

e-mail: gokhanerbag@hotmail.com

Submitted: 17.12 .2013

Accepted: 25.02 .2014 